\title{
O AMBIENTE INSTITUCIONAL DA PRODUÇÃO DE JUTA NO ESTADO DO PARÁ ENTRE AS DÉCADAS DE 1940 E 1990
}

\author{
Zilda Cohen Santos ${ }^{1}$ \\ João Pereira dos Santos ${ }^{2}$ \\ Tayla de Paula Lima ${ }^{3}$ \\ Elisane da Conceição Santos ${ }^{4}$
}

\section{INTRODUÇÃO}

A juta importada da Ásia foi por muito tempo a principal matéria-prima da incipiente indústria de aniagem brasileira que se desenvolveu a reboque da produção cafeeira nacional desde o final do século XIX. Conforme Matos (1996), apesar da forte relação existente entre esses dois ramos da atividade econômica nacional, a relação entre eles sempre foi conflituosa. De um lado os cafeicultores reclamavam que havia um excesso de protecionismo à indústria nacional, por meio das elevadas tarifas alfandegárias de importação da sacaria importada, de outro os industriais da aniagem se queixavam das tarifas alfandegárias para importação da juta asiática.

Esses conflitos perduraram por longos anos, levando muitos políticos, agrônomos e empresários a defender a inserção da cultura da juta ao solo brasileiro, culminando com inúmeras iniciativas experimentais no Estado de São Paulo, algumas delas financiadas pelos próprios industriais, nas décadas de 1910 e 1920. Porém, foi somente a experiência de cultivo realizada no Estado do Amazonas que retornou resultados positivos (MATOS, 1996).

A experiência de sucesso de cultivo da juta no Estado do Amazonas foi fruto de uma cooperação entre o governo brasileiro e o governo japonês. A imigração japonesa tinha como objetivo controlar a explosão demográfica no Japão e enviar força de trabalho para o Brasil, sobretudo para a Amazônia (IKEGAMI, 2009). Por outro lado, o Brasil precisava de mão-de-

\footnotetext{
1 Doutora em Desenvolvimento Rural pela Universidade Federal do Rio Grande do Sul. Professora Adjunta II do Programa de Ciências Econômicas e Desenvolvimento Regional da Universidade Federal do Oeste do Pará. E-mail: zildagama@yahoo.com.br.

2 Doutor em Economia pela Universidade Federal do Rio Grande do Sul. Professor Adjunto II da Faculdade de Economia da Universidade Federal do Pará. E-mail: jotapereirasantos@yahoo.com.br

${ }^{3}$ Acadêmica do curso de Ciências Econômicas da Universidade Federal do Oeste do Pará. E-mail: tayla_dpl@live.com

${ }^{4}$ Acadêmica do curso de Ciências Econômicas da Universidade Federal do Oeste do Pará. E-mail: elisanests@gmail.com
} 
obra para desenvolver a cultura da juta, uma vez que de acordo com Matos (1996) esse sempre foi um dos gargalos das experiências anteriores.

Essa cooperação foi iniciada ainda no final do século XIX e durante os anos de 19251929 começou a tomar forma com as ações de fortes incentivos do governo japonês, subsidiando pagamentos integrais para custeio da viagem aos interessados em emigrar para o Brasil. Ou seja, o governo agiu durante todo o processo e em todos os estágios, desde o financiamento das viagens até as pesquisas já em solo brasileiro.

Kotario Tuji, um dos imigrantes pioneiros, iniciou o cultivo das primeiras mudas de juta trazidas do Ceilão, na região do Médio Amazonas, sem, contudo, obter sucesso. Tal fracasso inicial não foi suficiente para desestimular os primeiros imigrantes, entre eles Ryoto Oyama, que por conta das similaridades das áreas de várzea da Amazônia com as áreas alagadas da Índia viam um imenso potencial para a cultura da juta (IKEGAMI, 2009; HOMMA, 2009).

Esse impulso inicial foi seguido pela criação de um conjunto de instituições e organizações que conformaram um ambiente institucional capaz de fomentar a cultura da juta e expandi-la pelos Estados do Amazonas e do Pará, transformando este último no maior produtor nacional e conduzindo o Brasil a quarta posição mundial durante a década de 1960.

Nesse contexto, esse trabalho tem como objetivo apresentar os resultados de uma pesquisa que buscou identificar as instituições e organizações criadas para impulsionar a cultura da juta no Estado do Pará, bem como identificar e analisar quais fatores institucionais limitaram a sua expansão e conduziram ao declínio da produção a partir do final da década de 1980.

Para tanto, o trabalho está sustentado nos pressupostos teóricos da Nova Economia Institucional (NEI) de Douglas North que afirma que as instituições têm um importante papel no processo de coordenação das atividades econômicas (NORTH, 1990). Desse modo compreender o ambiente institucional no qual uma atividade econômica está imersa é fundamental para um amplo alcance dos fatores que impulsionaram e/ou restringiram a atividade.

$\mathrm{O}$ artigo está dividido em três seções além desta introdução. A próxima seção trata dos aspectos teóricos da NEI no que tange ao ambiente institucional, em seguida são analisados os fatores de expansão e de declínio da atividade a partir da perspectiva institucionalista e por último apresenta-se as considerações finais. 


\section{A ABORDAGEM DA NOVA ECONOMIA INSTITUCIONAL}

A abordagem da NEI parte do princípio que as instituições podem ser geradoras de incentivos ou definidora de restrições à atividade econômica, ou seja, os novos institucionalistas, assim como os precursores dessa linha de pensamento, assumem que as instituições têm papel importante e por isso devem ser consideradas nas análises econômicas. Porém, diferentemente dos antigos institucionalistas, os novos mantêm alguns dos princípios teóricos da economia neoclássica, não rompendo completamente com esta última abordagem.

Independentemente das similaridades e diferenças entre essas duas correntes de pensamento o fato de trazerem as instituições para o centro da análise econômica representa um avanço significativo no pensamento econômico. Desse modo, este trabalho se apropria dos avanços proporcionados pelos institucionalistas, sobretudo pela NEI, para compreender o ciclo produtivo da juta no Estado do Pará entre as décadas de 1940 e 1990.

Para tanto é importante primeiramente compreender o conceito de instituições, que na visão de North (1990, p. 3, tradução nossa) "são as regras do jogo em uma sociedade ou, mais formalmente, são as restrições elaboradas pelos homens que dão forma à interação humana. Em consequência, elas estruturam incentivos no intercâmbio entre os homens, quer seja ele político, social ou econômico".

Essas instituições podem ser tanto formais quanto informais. As instituições formais são de acordo com North (1990) de três tipos: as regras políticas (aqui também incluindo as jurídicas), as regras econômicas e os contratos. Para ele as regras políticas definem a estrutura básica de decisão política, enquanto as regras econômicas definem os direitos de propriedade e os contratos a provisão específica para acordos de troca, ou seja, das transações.

As regras informais segundo North (1990, p. 37, tradução nossa) "surgem da informação socialmente transmitida e são parte da herança que nós chamamos de cultura". Os estudiosos da NEI, apesar dos esforços, não avançaram no desenvolvimento de um modelo teórico que incorporasse essas regras informais nas análises, cabendo os avanços dessa área aos pesquisadores da sociologia econômica.

Não obstante o reconhecimento da importância dessas regras informais no processo de interação humana, elas ficaram de fora das análises propostas nesse trabalho, por compreenderse que um estudo específico precisaria ser realizado com esse propósito. 
O conjunto dessas regras foi chamado por North e Davis (1971) de ambiente institucional, sendo este, portanto, capaz de definir padrões para interação humana e coordenar a atividade econômica, como pode ser sintetizado na Figura a seguir.

Nesse sentido, este trabalho buscou identificar e analisar as regras formais criadas durante o período de expansão e de declínio do ciclo produtivo da juta no Estado do Pará que conformaram o ambiente institucional que definia os padrões da atividade. Pretende ainda identificar e analisar as organizações que surgiram como mecanismos de apoio e fomento para atividade tendo como ponto de partida dessa última a compreensão de que as organizações são “grupos de indivíduos vinculados por algum propósito comum” (NORTH, 1990, p. 5, tradução nossa).

Portanto, assim como as instituições, as organizações também promovem a estrutura para interação humana. "As organizações incluem órgãos políticos (partidos, Senado, prefeituras, agências reguladoras), econômicos (firmas, sindicatos, fazendas familiares, cooperativas), sociais (igrejas, clubes, associações atléticas), educacionais (escolas, universidades)" (NORTH, 1990, p. 5, tradução nossa).

O levantamento dos dados e informações apresentados foi realizado em fontes bibliográficas, principalmente em trabalhos acadêmicos publicados anteriormente, bem como em fontes documentais, tais como Diário Oficial, jornais e revistas de circulação local e documentos oficiais de organizações. 
Figura 1 - O ambiente institucional segundo Douglas North (1990)

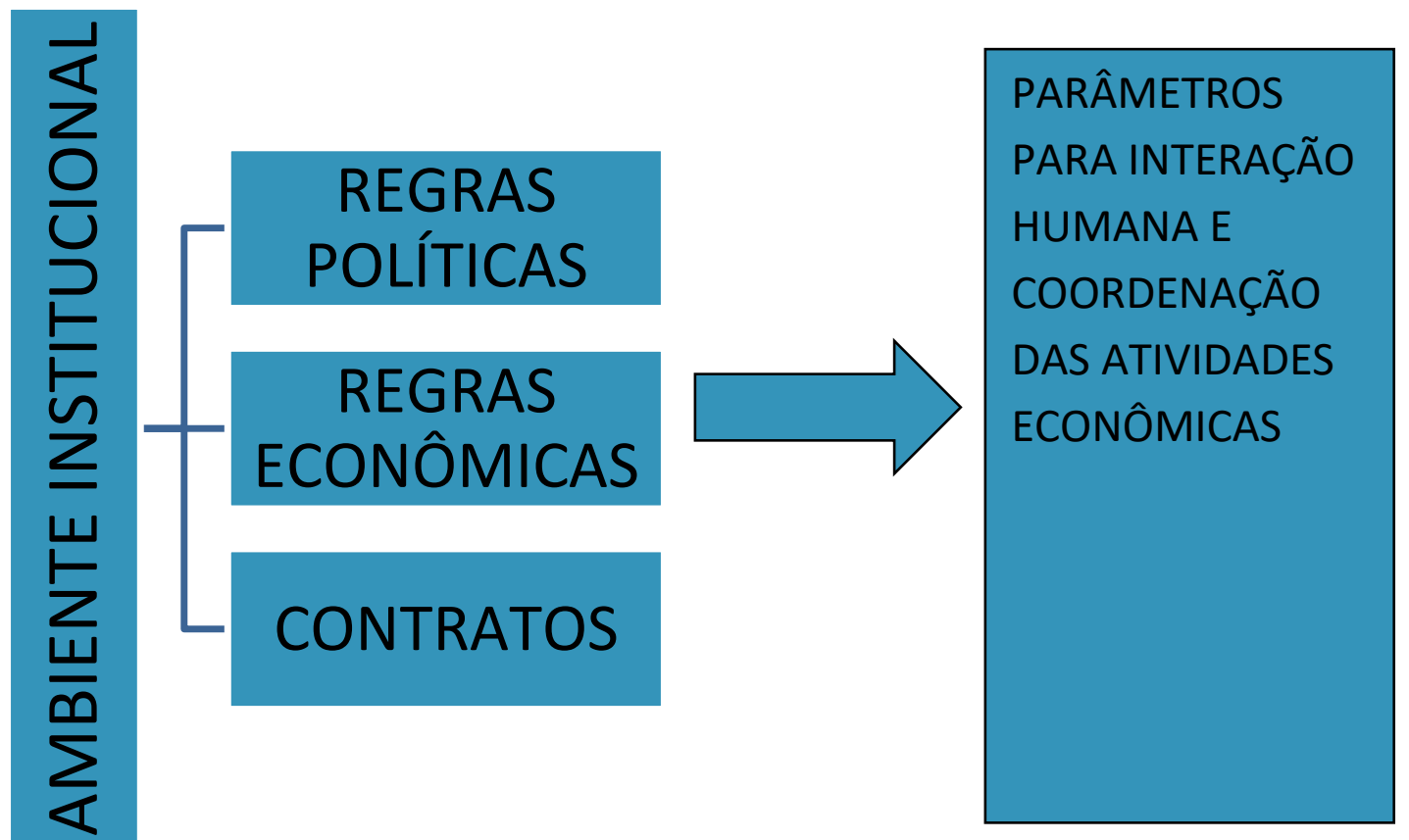

Fonte: Elaboração dos autores

As análises apresentadas na próxima seção têm como base as informações e dados levantados durante a pesquisa e tem como eixo norteador a premissa institucionalista de que as instituições podem ser promotoras de incentivos ou geradoras de restrições à atividade econômica.

\section{O AMBIENTE INSTITUCIONAL DA PRODUÇÃO DE JUTA NO ESTADO DO PARÁ}

A cultura da juta foi primeiramente introduzida no Estado do Amazonas, em 1929 e em 1930 foi fundada a Companhia Industrial Amazonense S.A (MATOS, 1996). Com o sucesso eminente e a grande demanda pela fibra para a produção de sacaria para a exportação do café, os japoneses começaram a vislumbrar a necessidade de expansão das áreas cultivadas para o Estado do Pará, mais precisamente para região do Baixo Amazonas ${ }^{5}$, cujas características da

\footnotetext{
5 De acordo com o IBGE é uma mesorregião do Estado do Pará que compreende os municípios de: Faro, Juruti, Terra Santa, Óbidos, Oriximiná, Alenquer, Belterra, Curuá, Mojui dos Campos, Monte Alegre, Placas, Prainha, Santarém, Almerim e Porto de Moz. Porém, a cultura da juta desenvolveu-se apenas nos municípios com áreas de várzea, ou seja, nos municípios às margens do rio: Santarém, Alenquer, Óbidos, Oriximiná e Monte Alegre.
} 
várzea se assemelhavam a região do Amazonas onde a juta vinha sendo cultivada, chamada de Médio Amazonas, com destaque para o município de Parintins.

Assim em 1938 a cultura da juta foi introduzida no Estado do Pará e logo ganhou impulso, vivendo um período de expansão até 1965, como pode ser observado no Gráfico 1 a seguir. Ao longo da década de 1960, no auge do crescimento, o Pará foi responsável, em média, por um quarto da produção nacional, contribuindo para o país tornar-se autosuficiente na produção de juta.

De acordo com Winklerprins (2006) seis foram os fatores que favoreceram a expansão da juta no Estado do Pará: 1) a demanda de fibra para produção de sacaria; 2) características físicas da região semelhantes a da Ásia; 3) chegada dos colonos japoneses ao Brasil; 4) fácil aceitação dos pequenos produtores de várzea à cultura da juta, além disso havia uma mão-de-obra sobressalente da produção de látex que tinha entrado em decadência; 5) o declínio da produção de juta na Ásia durante a $2^{\circ}$ guerra mundial e; 6) a ideia subjacente do governo brasileiro de que a juta seria um fator de interligação entre o Norte e o Sul do Brasil.

\section{Gráfico 1 - Produção brasileira e paraense de juta em toneladas}

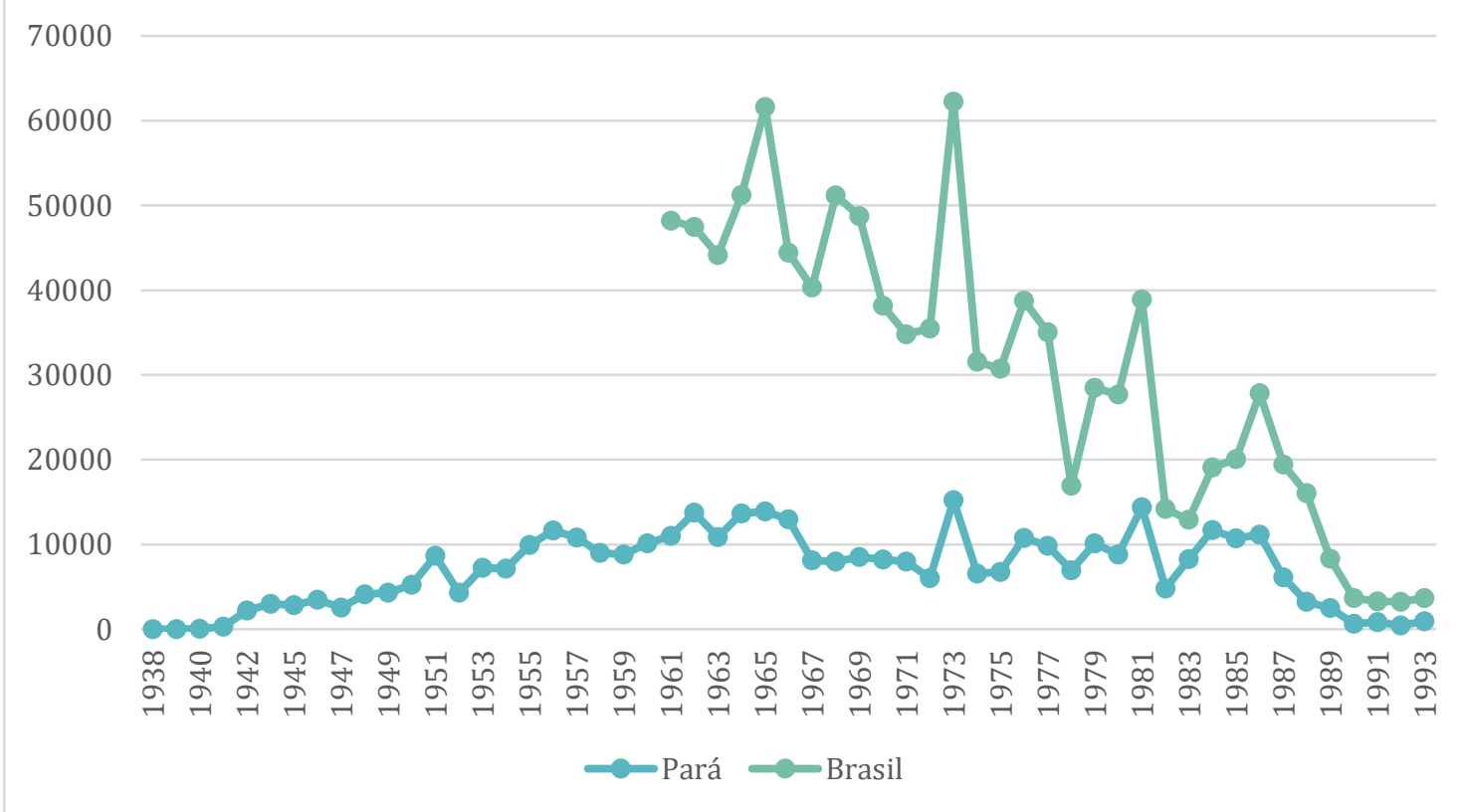

Fonte: Elaborado pelos autores (2020)

Dados do Pará (IFIBRAM, 2020).

Dados do Brasil (FAOSTAT, 2020)

Observação: Os dados disponíveis na base de dados FAOSTAT para o Brasil começam em 1961 
O Gráfico 1 mostra, que não obstante o Estado do Pará viver um período de forte expansão no começo do ciclo, durante a década de 1940, com elevadas taxas de crescimento, a produção de juta sempre oscilou, apresentando períodos de crescimento seguido de períodos de declínio. Tal tendência mostra-se presente também na produção brasileira e é característica marcante dos produtos agrícolas de baixo valor agregado, o que demonstra que a atividade dependia de uma série de fatores políticos, econômicos e institucionais, além das questões estritamente geofísicas.

Essas oscilações do ciclo produtivo se intensificaram a partir da década de 1960, sendo o pico máximo de produção registrado em 1973 com 15.210 toneladas produzidas pelo Estado do Pará e 62.226 pelo Brasil. Um crescimento de $154 \%$ que foi seguido por um decréscimo de $57 \%$ na produção paraense de juta.

A partir de 1986 a produção entrou em declínio, não voltando mais aos patamares anteriores de produção. Esse declínio se deve, de acordo com Winklerprins (2006), principalmente a quatro fatores: 1) redução da demanda para produção da sacaria, devido a substituição das sacas de fibra pelas sacas de plástico e também devido a redução das exportações brasileiras; 2) gargalo na mão-de-obra que impedia a maximização da produção; 3) qualidade inferior da juta amazônica comparada a juta asiática; 4) liberalização do mercado brasileiro com o fim do imposto de importação.

Como se vê tanto os fatores de impulso quanto os de declínio estão relacionados a questões institucionais e organizacionais, mais do que a fatores geográficos ou climáticos, o que justifica a análise proposta nesse trabalho e apresentada na próxima seção.

\subsection{O período de expansão da produção de juta no Estado do Pará}

Visando expandir a produção de juta dentro do Estado do Pará, considerando que a região do Baixo Amazonas apresentava as mesmas características geofísicas da região do Médio Amazonas onde o cultivo da juta se iniciou, Kotario Tuji e Toshio Tsukumo, em 1938 solicitaram o incentivo do Governo do Estado do Pará para iniciar em caráter experimental o cultivo da juta no Estado. Tal demanda, foi atendida pelo então interventor do Estado do Pará, José da Gama Malcher que definiu por meio do Decreto nº 3065 as regras para essa experiência, dentre as quais destacam-se as apresentadas no Quadro 1 a seguir. 
Usando a tipologia definida por North (1990) para as instituições formais, o Decreto $\mathrm{n}^{\circ}$ 3065 foi um contrato entre o Estado do Pará e uma dupla de produtores interessados em produzir a juta no Estado, assim antes mesmo de funcionar como um incentivo de amplo alcance, ou uma instituição de fomento à produção de juta, o Decreto foi uma instituição que favorecia especificamente um grupo. Apesar disso, vale destacar que dado o seu papel na mitigação das incertezas com o transporte dos colonos (ou seja garantia da mão-de-obra) e a garantia do controle do preço de compra, por meio da concessão de monopólio pelo Estado é inegável que esse contrato representou incentivos, para o impulso inicial à cultura da juta no Estado do Pará.

Especialmente o compromisso de não conceder a outras companhias os mesmos benefícios garantia aos pioneiros o monopólio na produção de juta. Assim, as repercussões dessa regra foram limitadas no sentido de que a cadeia produtiva estruturada nesse primeiro ciclo de expansão que compreendeu a inserção da juta na região e foi até a década de 1960 , estava sustentada no que diversos autores chamam de patronagem (GENTIL, 1983; WINKLERPRINS, 2006).

Vale destacar que a patronagem pode ser classificada na tipologia de North (1990) como uma instituição informal, que já existia na região amazônica desde o ciclo produtivo da borracha e que apenas se perpetuou por meio de um processo adaptativo para a atividade de cultivo da juta e assim, se sobrepôs a. instituição formal.

De acordo com Gentil (1983) esse sistema funcionava da seguinte forma: o patrão, geralmente um comerciante que detinha capital e estava instalado na área de várzea, fornecia as sementes de juta para os agricultores, estes por sua vez compravam os mantimentos no estabelecimento do comerciante e pagavam com a produção de juta. O patrão, em geral possuía um barco, trazia para Santarém a produção e vendia para os estabelecimentos de prensagem.

Estando em conformidade com a instituição informal, este processo de produção não favorecia o avanço tecnológico, mas a exploração a vantagem pessoal e discriminação, tornando-se extremamente desfavorável ao agricultor. Esse sistema se sustentou por longos anos, por diversos motivos, mas os principais foram: a ausência de uma instituição financeira na região que pudesse financiar a produção dos pequenos agricultores e o interesse dos patrões e dos proprietários das casas de prensagem em manter o sistema que era favorável a eles. 
Quadro 1 - Síntese das obrigações contratuais do Decreto no 3065/1938

\begin{tabular}{|c|c|}
\hline Obrigações do Estado & $\begin{array}{l}\text { Obrigações dos proponentes (Tuji e } \\
\text { Tsukumo) }\end{array}$ \\
\hline $\begin{array}{l}\text { - Facilitar a compra de terrenos } \\
\text { - Caso a Companhia fosse criada: } \\
\text { o conceder terras até o limite de } \\
10.000 \text { hectares } \\
\text { Redução de impostos estaduais } \\
\text { e municipais variando de } \\
100 \% \text { do } 1^{\circ} \text { ao } 4^{\circ} \text { ano a } 20 \% \text { do } \\
15^{\circ} \text { ao } 20^{\circ} \text { ano } \\
\text { Transporte gratuito dos } \\
\text { imigrantes e colonos do porto } \\
\text { de Belém até as plantações } \\
\text { Impostos estaduais } \\
\text { municipais nunca excederiam } \\
100 \text { réis por quilo } \\
\text { - Não conceder a outras Companhias } \\
\text { formadas ou por formar os mesmos } \\
\text { benefícios } \\
\text { - Facilitar a aquisição de terrenos para } \\
\text { instalação da Companhia } \\
\text { Intermediar junto ao Governo Federal: } \\
\text { A entrada de } 100 \text { famílias } \\
\text { japonesas por ano } \\
\text { Isenção de impostos } \\
\text { alfandegários de máquinas e } \\
\text { equipamentos } \\
\text { Passagens gratuitas dentro do } \\
\text { Brasil para colonos } \\
\text { contos de réis }\end{array}$ & $\begin{array}{l}\text { - Compromisso em manter famílias de } \\
\text { agricultores nos terrenos onde as } \\
\text { experiências fossem realizadas } \\
\text { - Criação de uma Companhia após o } \\
\text { período de experiência de } 3 \text { anos caso } \\
\text { a experiência fosse favorável } \\
\text { - Distribuição do capital da firma entre } \\
\text { brasileiros e japoneses } \\
\text { - Fornecer 5\% das sementes } \\
\text { selecionadas após o período de } \\
\text { experiência ao Governo para serem } \\
\text { plantadas em outras regiões do Estado }\end{array}$ \\
\hline
\end{tabular}

Fonte: Decreto no 3065 de 16 de agosto de 1938

Com a total aclimatação da juta à região de várzea do Baixo Amazonas, bem como da habituação da mão-de-obra existente na região ao sistema de produção, o cultivo da juta rapidamente se expandiu, aumentando em 10 vezes ao longo dos 3 anos de experiência, entre 1938 e 1940 (saltou de 5 para 52 toneladas). Esse impulso fez surgir em todo o Estado empresas de prensagem e exportação de fibra, como a FIBRASA e a JUTASA em Santarém, a CATA em Castanhal e a Perseverança em Belém. O próprio Tuji era dono de uma casa de prensagem e exportação de fibra, localizada em Santarém, a casa Boa Esperança (Tuji \& Cia). 
Ao longo da década de 1940 com a produção em ligeira expansão, Tuji começou a articular junto a outros comerciantes da região e ao governo estadual e federal apoio para a construção de uma fábrica de processamento da fibra de juta, de modo a completar o ciclo produtivo da fibra na própria região.

Sem capital próprio para a compra de máquinas e equipamentos que deveriam ser importados em virtude de não haver no Brasil uma indústria de bens de capital consolidada, bem como a inexistência de instituições financeiras para financiar essas aquisições, o único caminho para efetivação dessa fábrica seria por meio de apoio dos Governos Federal e Estadual.

Tristan (2016) afirma que a eleição de Getúlio Vargas foi fundamental para a efetivação dessa empreitada. Em seu segundo mandato como presidente da república através do Decreto $n^{\circ} 6.825$ de 7 de fevereiro de 1941, criou a Lei de Proteção da Indústria Juteira do Vale da Amazônia. Em sua terceira campanha presidencial em 1950, em uma passagem por Santarém, comprometeu-se a implementar políticas que fomentassem o desenvolvimento da Amazônia garantindo a sua integração com o resto do país. Nesse sentido, após a sua eleição, Getúlio Vargas criou em 1953 a Superintendência do Plano de Valorização Econômica da Amazônia (SPVEA) que tinha como objetivo conceder incentivos e fomentar o desenvolvimento da Amazônia.

Dessa forma, a criação da SPVEA representou um importante incentivo econômico às atividades produtivas da Amazônia, entre elas a produção de juta, uma vez que juntamente com a sua criação, foi instituído o Fundo de Valorização Econômica da Amazônia composto por recursos da União, dos Estados e dos municípios. Na acepção institucionalista a criação dessas regras bem como da organização responsável pela gestão foram incentivos às atividades produtivas. Entretanto, a organização da produção permaneceu inalterada em conformidade com a instituição da patronagem, portanto ineficiente, não havendo melhora da performance.

Assim, buscando se apropriar desses incentivos, em 1951 foi fundada a Fábrica de Fiação e Tecelagem de Juta de Santarém (TECEJUTA), com 17 sócios, entre eles Tuji, que na época era presidente da Associação de Juteiros, e se tornou o diretor-gerente da Companhia (TRISTAN, 2016). A TECEJUTA foi criada com o objetivo realizar o processamento da juta e transformá-la em sacaria na própria região produtora da fibra, logo buscava-se a formação de um arranjo organizacional que compreende-se grande parte da cadeia produtiva, desde o cultivo 
até a transformação em sacaria, localmente, visando ampliar os benefícios econômicos para a região.

Contudo, com a mudança no quadro político após a morte de Getúlio Vargas, e a consequente dificuldade para aquisição de máquinas e equipamentos, bem como do estabelecimento de infraestrutura básica para o funcionamento de uma fábrica, como a transmissão de energia, a TECEJUTA só iniciou as suas atividades em 1965 quando foi possível obter a licença de importação e os subsídios necessários para a compra de máquinas do Japão e da Inglaterra.

Isso demonstra as dificuldades institucionais inerentes a fundação de uma unidade produtiva no interior da Amazônia em um período em que a região sul e sudeste se encontravam no auge do seu processo de industrialização. Logo, observa-se que para industrializar a Amazônia fazia-se necessário a criação de um ambiente institucional formado por regras de incentivo, bem como organizações de fomento a atividade com um espectro de abrangência que fosse além dos incentivos financeiros, mas que abrangesse o fomento ao conhecimento, por exemplo.

Nesse sentido, alguns autores enfatizam a importância de outras organizações governamentais, mais precisamente organizações de pesquisa, no processo de expansão da cultura da juta no Estado do Pará, entre elas o Instituto Agronômico do Norte (IAN) criado em 1939 e posteriormente transformado em Embrapa Amazônia Oriental e a Associação de Crédito e Assistência Rural do Pará (ACAR- Pará) atual Empresa de Assistência Técnica e Extensão Rural do Estado do Pará (Emater- Pará) (HOMMA, 1995; GENTIL, 1983).

Porém, apesar desses esforços, para os empresários da indústria da tecelagem instalados na região, as iniciativas governamentais de fomento ainda eram incipientes e não atendiam as expectativas, principalmente após a década de 1970 quando a sacaria de fibra passou a sofrer a concorrência direta da sacaria de plástico e da fibra asiática que possuía qualidade superior à brasileira. Além disso, por conta do atraso tecnológico no desenvolvimento da semente e do sistema produtivo baseado em instituições arcaicas, a organização da produção na Amazônia apresentava alto custo de transporte e energia, baixa produtividade e preço elevado, de modo que um grupo de 27 indústrias do ramo da tecelagem criou em 1973 o Instituto de Fomento à Produção de Fibras Vegetais da Amazônia (IFIBRAM). 
O objetivo do IFIBRAM era fomentar a pesquisa para o aperfeiçoamento tecnológico da produção de juta, com o intuito de melhorar a qualidade, bem como ampliar a produção e reduzir custos. Apesar da iniciativa dos empresários, os resultados dos esforços foram pouco significativos e na década seguinte a produção de juta entrou em declínio, devido a diversos fatores que serão analisados na seção seguinte.

\subsection{O declínio da produção de juta no Estado do Pará}

A partir do pico produtivo em 1973 a produção de juta no Estado do Pará, bem como no Brasil, entrou em processo de declínio. Conforme apresentado anteriormente, na perspectiva de Winklerprins (2006), essa redução ocorreu devido a quatro fatores que serão analisados a seguir.

Primeiramente as sacas produzidas a partir do polipropileno, introduzidas no mercado brasileiro a partir da década de 1970, fizeram reduzir significativamente a demanda pelas sacas de fibra vegetal para armazenamento de produtos agrícolas, devido principalmente a redução dos custos de produção e de transporte que as sacas produzidas a partir de material sintético proporcionavam. Assim, não obstante as sacas de plástico sofrerem com a oscilação do preço do petróleo, sua principal matéria-prima e apresentarem para alguns especialistas qualidade inferior quando comparadas as sacas de fibra vegetal, elas rapidamente ganharam mercado reduzindo sensivelmente a demanda pelas sacas de juta e consequentemente reduzindo a produção dessa fibra (WINKLERPRINS, 2006).

Desde a década de 1920 havia uma intensa batalha dos cafeicultores do sudeste do país para reduzir custos de armazenamento do café, esses produtores consideravam elevados os custos de importação da fibra vegetal para a produção da sacaria e viviam em volta a tentativas de redução de tarifas de importação junto ao Governo Federal, sendo esta inclusive objeto de uma intensa disputa entre deputados do sudeste e do norte do país em 1948. Vale ressaltar que Getúlio Vargas retirou o imposto de exportação na constituição da década de 1930.

Para os produtores de juta a ausência a partir da década de 1970 de uma instituição (regra formal) que de alguma forma promovesse o protecionismo para a indústria de sacaria nacional foi um fator decisivo para que esta perdesse a batalha frente a inserção das sacarias sintéticas. Vale destacar que caso essa instituição formal existisse, ela continuaria sustentando as 
instituições informais na Amazônia, como a patronagem que por sua vez alimentavam o atraso no processo produtivo e o atraso tecnológico. A intenção do Governo principalmente a partir do Governo de Juscelino Kubistchek era combater definitivamente a prática do aviamento na Amazônia.

O segundo fator de declínio apontado por Winklerprins (2006) foi o gargalo na mão-deobra que impedia a maximização da produção. A cultura da juta sempre foi intensiva em mãode-obra e bastante insalubre com pouquíssimo desenvolvimento tecnológico ${ }^{6}$. A partir do momento que a pecuária começou a ser praticada nas áreas de várzea do Baixo Amazonas, parte da mão-de-obra migrou para essa atividade que exigia bem menos esforços e possibilitava um maior retorno financeiro. Além disso, a partir da década de 1970 houve na região, acompanhando uma tendência do país, um processo de urbanização e consequentemente um esvaziamento populacional nas áreas rurais.

Com relação a qualidade da juta amazônica, este é considerado pelos especialistas um ponto nefrálgico que reflete a falta de interesse dos governos que não estimularam a pesquisa para o desenvolvimento de tecnologias produtivas e para o melhoramento genético das sementes de juta, o que até hoje ainda é a principal necessidade e fator decisivo para a possibilidade da continuidade do plantio de juta de produtores que tentam reativar a cultura no Norte, principalmente no Amazonas. Não obstante os esforços do IAN e do IFIBRAM, nenhum avanço significativo foi efetivado. De modo oposto os países asiáticos avançaram no desenvolvimento de novas tecnologias e criaram organizações específicas para fomentar a cultura da juta, como a Índia que desde 1974 é a maior produtora mundial de juta (FERREIRA, 2016).

Essa falta de interesse se deveu ao pouco poder de barganha dos produtores de juta tendo em vista que a juta estava longe de ser um dos principais produtos de exportação do Brasil, além do que o desenvolvimento da semente não resolveria o problema do aviamento. Nesse período, o Governo estava mais preocupado em implementar culturas nos moldes da produção capitalista.

\footnotetext{
${ }^{6}$ Não é objetivo deste trabalho adentrar na tecnologia de produção, porém cabe comentar que de acordo com GENTIL (1983) ao longo dos anos o único instrumento desenvolvido localmente foi o tico-tico, um instrumento utilizado para realizar a cova onde a juta era plantada. O descortinamento era realizado manualmente e demandava um esforço físico muito grande dos agricultores.
} 
Na década de 1990 o Brasil iniciou um processo de liberalização econômica que foi efetivado com a criação de uma série de regras formais, entre elas o Decreto no 350 de 1991 que criou a Tarifa Comum do Sul. Tais regras objetivavam eliminar barreiras tarifárias e facilitar a entrada de produtos estrangeiros no país, entre essas regras, houve a eliminação das tarifas de importação da fibra de juta o que acabou facilitando a entrada da fibra asiática no país e eliminando de vez a capacidade competitiva da fibra nacional (WINKLERPRINS, 2006).

A próxima seção apresenta uma síntese das instituições e organizações que surgiram durante o ciclo da juta, identificando-as dentro da tipologia proposta por North (1990) e analisando-as como incentivos ou restrições à produção de juta do Estado do Pará.

\subsection{Síntese analítica}

O Quadro 2 a seguir apresenta a síntese analítica deste trabalho de acordo com a tipologia definida por North (1990). Além disso, o quadro mostra também os efeitos de identificados (incentivo ou restrição) para cada uma das instituições/organizações mapeadas.

\begin{tabular}{|c|c|c|c|}
\hline $\begin{array}{l}\text { Instituição/ } \\
\text { Organização }\end{array}$ & Tipologia (North 1990) & Síntese & Efeito \\
\hline $\begin{array}{ll}\text { Decreto } & n^{\circ} \\
3065 / 1938 & \end{array}$ & $\begin{array}{l}\text { Instituição formal do tipo } \\
\text { contrato }\end{array}$ & $\begin{array}{llr}\text { Concessão } & & \text { de } \\
\text { incentivos à dois } \\
\text { japoneses para o } \\
\text { cultivo da juta no } \\
\text { Estado Pará }\end{array}$ & $\begin{array}{l}\text { Incentivo ao início } \\
\text { da cultura de juta } \\
\text { no Estado. } \\
\text { Restrição à } \\
\text { concorrência }\end{array}$ \\
\hline $\begin{array}{ll}\text { Lei } & \mathrm{n}^{\mathrm{o}} \\
1806 / 1953 & \end{array}$ & $\begin{array}{l}\text { Instituição formal do tipo } \\
\text { econômica }\end{array}$ & $\begin{array}{lr}\text { Criação de } & \text { uma } \\
\text { organização } & \text { a } \\
\text { SPVEA para gerir o } \\
\text { Fundo } & \text { de } \\
\text { Valorização } & \text { da } \\
\text { Amazônia } & \end{array}$ & $\begin{array}{lr}\text { Incentivo, } & \text { com } \\
\text { recursos } & \text { para } \\
\text { financiar } & \text { o } \\
\text { processo produtivo }\end{array}$ \\
\hline $\begin{array}{l}\text { Criação da } \\
\text { TECEJUTA }\end{array}$ & Organização econômica & $\begin{array}{llr}\begin{array}{l}\text { Criação de } \\
\text { fábrica }\end{array} & & \text { uma } \\
\text { processamento } & \text { da } \\
\text { matéria } & & \text { prima } \\
\text { próximo à } & \text { região } \\
\text { onde a fibra } & \text { era } \\
\text { cultivada } & & \\
\end{array}$ & $\begin{array}{l}\text { Incentivo, } \\
\text { possibilitando } \\
\text { beneficiamento na } \\
\text { própria região }\end{array}$ \\
\hline $\begin{array}{l}\text { IAN/Embrapa } \\
\text { Amazônia } \\
\text { Oriental }\end{array}$ & $\begin{array}{l}\text { Organização pública de } \\
\text { pesquisa }\end{array}$ & $\begin{array}{l}\text { Buscava distribuir } \\
\text { sementes de juta aos } \\
\text { agricultores }\end{array}$ & $\begin{array}{l}\text { Incentivo } \\
\text { expansão } \\
\text { produção }\end{array}$ \\
\hline
\end{tabular}




\begin{tabular}{|c|c|c|c|}
\hline & & & $\begin{array}{l}\text { Restrição, pois não } \\
\text { desenvolveu } \\
\text { melhoramentos } \\
\text { genéticos e nem no } \\
\text { processo produtivo }\end{array}$ \\
\hline IFIBRAN & $\begin{array}{l}\text { Organização privada de } \\
\text { pesquisa }\end{array}$ & $\begin{array}{l}\text { Buscava desenvolver } \\
\text { pesquisas para } \\
\text { melhoramento do } \\
\text { processo produtivo }\end{array}$ & $\begin{array}{l}\text { Incentivo, por } \\
\text { estimular estudos } \\
\text { para } \quad \text { o } \\
\text { aperfeiçoamento } \\
\text { das sementes } \\
\text { disponibilizadas } \\
\text { para cultivo }\end{array}$ \\
\hline $\begin{array}{ll}\text { Decreto } & \mathrm{n}^{\circ} \\
350 / 1991 & \end{array}$ & $\begin{array}{l}\text { Instituição formal do tipo } \\
\text { econômica }\end{array}$ & \begin{tabular}{lr}
\multicolumn{3}{c}{ Criou a tarifa comum } \\
no âmbito do \\
Mercosul, \\
refletiu-se que \\
eliminação na \\
tarifas alfandegárias \\
de importação de juta
\end{tabular} & $\begin{array}{l}\text { Restrição, ao abrir } \\
\text { o mercado nacional } \\
\text { à concorrência da } \\
\text { juta asiática }\end{array}$ \\
\hline
\end{tabular}

Fonte: Elaborado pelos autores, 2020

Observa-se que que mesmo as instituições e organizações que trouxeram incentivo à produção de juta no Estado do Pará representaram também restrições à atividade. Ou seja, o cultivo da juta e o seu beneficiamento nunca foram considerados atividades estratégicas que merecessem a formatação de um arranjo institucional adequado ao estímulo e desenvolvimento da atividade.

O processo produtivo, durante muito tempo, permaneceu enraizado em uma instituição informal, a patronagem, que por conveniência não permitia o desenvolvimento de novas tecnologias, mantendo o processo produtivo extremamente insalubre. Nenhuma instituição formal foi criada para combater essa prática.

Esses fatores foram criando gargalos que culminaram com o Decreto $n^{\circ} 350$ de 1991 que eliminou as tarifas alfandegárias e abriu o mercado brasileiro à concorrência da juta asiática de melhor qualidade e mais barata, levando a atividade ao declínio.

\section{CONSIDERAÇÕES FINAIS}

A produção de juta no Estado do Pará foi responsável, durante muito tempo por um quarto da produção nacional, tendo o seu auge na década de 1960, o que contribuiu para o Brasil tornar- 
se auto suficiente na produção dessa fibra, tão utilizada na fabricação de sacaria para a exportação de produtos agrícolas.

Porém, a análise do ambiente institucional mostrou que apesar de no período de produção, entre as décadas de 19400 e 1990, terem sido criadas instituições e organizações de fomento e incentivo à produção de juta, tais instituições apresentavam limitações que acabavam não apenas não produzindo os incentivos pretendidos, como também trazendo restrições à atividade.

Assim, pelas análises apresentadas, fica evidente que o ambiente institucional foi fator de extrema relevância tanto na expansão quanto na retração da produção de juta, ratificando os avanços teóricos da NEI que afirmam que as instituições podem funcionar tanto como incentivos quanto restrições às atividades econômicas.

Esses resultados confirmam a importância da incorporação da perspectiva institucionalista na análise dos fenômenos econômicos, uma vez que essa perspectiva permite que as análises extrapolem os aspectos mercadológicos, de oferta e demanda, possibilitando uma ampliação dos olhares e perspectivas.

\section{REFERÊNCIAS BIBLIOGRÁFICAS}

BRASIL. Decreto $\mathbf{n}^{0} 6825$ de 07 de fevereiro de 1941. Aprova as especificações e Tabelas para a classificação e fiscalização da exportação das fibras conhecidas sob a denominação de "Junta Indiana Cultivada no Brasil, visando a sua padronização. Rio de Janeiro, 1941.

BRASIL. Lei $n^{\circ} 1806$ de 06 de janeiro de 1953. Dispõe sobre o Plano de Valorização Econômica da Amazônia cria a Superintendência da sua execução e dá outras providências. Rio de Janeiro, 1953.

BRASIL. Decreto n⿳350 de 21 de novembro de 1991. Promulga o Tratado para a Constituição de um Mercado comum entre a República Argentina, a República Federativa do Brasil, a República do Paraguai e a República Oriental do Uruguai. Brasília, 1991.

DAVIS, Lance E; NORTH, Douglas. Institutional change and american economic growth. Cambridge: Cambridge University Press, 1971

FAOSTAT. Crops - download databases. Disponível em fao.org/faostat/en/\#/data/QC. Acesso em 17 de julho de 2020.

FERREIRA, Aldenor da Silva. Fios dourados dos trópicos: culturas, histórias, singularidades e possibilidades (juta-malva - Brasil - Índia). Tese de Doutorado. Instituto de Filosofia e Ciências Humanas. Universidade Estadual de Campinas, 2016.

FERREIRA, Aldenor da Silva; HOMMA, Alfredo Kingo Oyama. A colonização britânica e o declínio da produção de juta indiana: singularidades e possibilidades para Amazônia. Fronteiras: revista de História, v. 21, n. 37, jan/jun 2019 
GENTIL, Janete Marília Lobato. A juta na agricultura de várzea na área de Santarém Médio Amazonas. (Dissertação de Mestrado). Mestrado em Geografia. Universidade Federal de Pernambuco. 143 f. 1983

IFIBRAM. Planilha com dados da produção de juta no Estado do Pará de 1938 até 2010. Documento impresso, 2020.

IKEGAMI, Antão Shinobu. A fibra e o sonho. Editora A Gazeta Maçônica Ltda: São Paulo, 2009

HOMMA, Alfredo Kingo Oyama. Os japoneses na Amazônia e sua contribuição para o desenvolvimento agrícola. Somalu, n.9, n. 1, jan/jun 2009.

HOMMA, Alfredo Kingo Oyama. A civilização da juta na Amazônia: expansão e declínio. Anais do Congresso Brasileiro de Economia e Sociologia Rural, 1995.

MATOS, Maria Izilda Santos. Trama e poder: trajetória e polêmica em torno da indústria de juta. 2 ed. Rio de Janeiro: Sette Letras, 1996

NORTH, Douglas C. Instituions, institutional change and economic performance.

Cambridge: Cambridge University Press, 1990.

PARÁ. Decreto no 6.035 de 16 de agosto de 1938. Concede auxílio ao serviço de experiência do plantio de juta. Belém, 1938.

TRISTAN, Daniela Rebelo Monte. Trabalhadores da Tecejuta: experiência operária e construção da memória numa fábrica têxtil do Oeste do Pará (1951 - 1990). Dissertação de Mestrado. Programa de Pós-graduação em História. Universidade Federal do Amazonas, 2016.

WINKLERPRINS, Antoinette M. G. A. Jute cultivation in the Lower Amazon, 1940-1990: an ethnographic account from Santarém, Pará, Brazil. Journal of Historical Geography, 32, 2006

Recebido em Janeiro de 2020.

Aceito para Publicação em Maio de 2020. 


\title{
O AMBIENTE INSTITUCIONAL DA PRODUÇÃO DE JUTA NO ESTADO DO PARÁ ENTRE AS DÉCADAS DE 1940 E 1990
}

\section{RESUMO}

A expansão do cultivo da juta em território brasileiro liderada pelos imigrantes japoneses encontrou solo fértil nas várzeas dos Estados do Pará e Amazonas, levando o primeiro a ser responsável por um quarto da produção nacional na década de 1960. Este artigo tem como objetivo explicar tanto a expansão quanto a queda na produção por meio dos fatores institucionais, para tanto utiliza o arcabouço teórico da Nova Economia Institucional de Douglas North. Os resultados mostraram que mesmo as instituições e organizações que trouxeram incentivo à produção representaram também restrições à atividade, permanecendo a produção enraizada em antigos processos produtivos que limitaram o avanço tecnológico. Dessa forma, a inexistência de um arranjo institucional adequado ao desenvolvimento da atividade está no cerne do fracasso da cultura da juta no Estado.

Palavras-chave: Juta, Pará, Ambiente Institucional

\section{THE INSTITUTIONAL ENVIRONMENT OF JUTE PRODUCTION IN THE PARÁ STATE BETWEEN 1940 AND 1990}

\begin{abstract}
The expansion of jute cultivation in Brazilian territory led by Japanese immigrants found fertile soil in the floodplains in the Pará and Amazonas States, leading the former to be responsible for a quarter of national production in the 1960s. This article aims to explain both the expansion as well as the fall in production through institutional factors, for this purpose it uses the theoretical framework of the New Institutional Economy by Douglas North. The results showed that even the institutions and organizations that brought an incentive to production also represented restrictions on activity, with production remaining rooted in old production processes that limited technological progress. Thus, the lack of an adequate institutional arrangement for the development of the activity is at the heart of the jute culture failure in the State.
\end{abstract}

Key-words: Jute, Pará, Institutional Environment,

JEL: N56 